CARPATHIAN J. MATH.

Volume 38 (2022), No. 1,

Pages 35 - 46
Online version at https : //www . carpathian. cunbm. utcluj. ro/

Print Edition: ISSN 1584 - 2851; Online Edition: ISSN 1843 - 4401

DOI: https://doi.org/10.37193/CJM.2022.01.04

Dedicated to the memory of Academician Mitrofan M. Choban (1942-2021)

\title{
Maia type fixed point theorems for some classes of enriched contractive mappings in Banach spaces
}

\author{
VASILE BERINDE
}

ABSTRACT. We give some extensions of the beautiful 1968 fixed point theorem of Maia [Maia, M. G. Un'osservazione sulle contrazioni metriche. (Italian) Rend. Sem. Mat. Univ. Padova 40 (1968), 139-143] to three classes of enriched contractive mappings in Banach spaces: enriched contractions, Kannan enriched contractions and Ćirić-Reich-Rus contractions.

\section{INTRODUCTION}

The metric fixed point theory has developed by and around Banach's contraction mapping principle, which, in the case of a metric space setting, can be briefly stated as follows.

Theorem 1.1. Let $(X, d)$ be a complete metric space and $T: X \rightarrow X$ a contraction, i.e., a map satisfying

$$
d(T x, T y) \leq a d(x, y), \quad \text { for all } x, y \in X,
$$

where $0 \leq a<1$ is constant. Then: $(p 1) T$ has a unique fixed point $p$ in $X$ (i.e., $T p=p$ ); $(p 2)$ The Picard iteration $\left\{x_{n}\right\}_{n=0}^{\infty}$ defined by

$$
x_{n+1}=T x_{n}, \quad n=0,1,2, \ldots
$$

converges to $p$, for any $x_{0} \in X$.

Remark 1.1. A map satisfying $(p 1)$ and $(p 2)$ in Theorem 1.1 is said to be a Picard operator, see [71], [72] for more details.

Theorem 1.1, which has been stated first by Banach [8] in the setting of a complete normed linear space (what we call now a Banach space), has been transposed by Caccioppoli [26] to metric spaces.

Being a simple and versatile tool in establishing existence and uniqueness theorems for solving many kinds of nonlinear problems - especially when the setting is a Banach space - Theorem 1.1 plays a very important role in nonlinear analysis.

This fact motivated researchers to try to extend and generalise Theorem 1.1 in such a way that its area of potential applications should be enlarged as much as possible, see the monographs [11], [70]-[73] for many of such kind of generalizations.

In 1968, by distributing the assumptions on two comparable metrics $d$ and $\rho$ defined on the set $X$, Maia [44] established a very interesting and beautiful generalization of Theorem 1.1 .

Received: 31.03.2021. In revised form: 20.04.2021. Accepted: 27.04. 2021

2010 Mathematics Subject Classification. 47H10, 47H05, 47H09, 47H14, 54H25.

Key words and phrases. Banach space, enriched contraction, fixed point, Ćirić-Reich-Rus contraction . 
Theorem 1.2 ([44], Teorema 1). Let $X$ be a set endowed with two metrics $d$ and $\rho$ satisfying

$$
d(x, y) \leq \rho(x, y), \text { for all } x, y \in X .
$$

Suppose

(i) $(X, d)$ is a complete metric space;

(ii) $T: X \rightarrow X$ is continuous with respect to $d$;

(iii) $T$ is a contraction with respect to $\rho$, that is,

$$
\rho(T x, T y) \leq a \rho(x, y), \quad \text { for all } x, y \in X,
$$

where $0 \leq a<1$ is constant. Then $T$ is a Picard operator.

Remark 1.2. It is easily seen that, if $d \equiv \rho$, then Theorem 1.2 reduces to Theorem 1.1.

Due to the beautiful idea on which the Maia's fixed point theorem is builded, it attracted much interest and still attracts many researchers working in fixed point theory, see Albu [1], Ansari et al. [4], Balazs [5]-[7], Bayen [9], Berinde [10], Berinde and Vetro [22], Bhola and Sharma [23], Bylka [25], Dhage [30]-[33], Dhage and Dhobale [32], Filip [34], [35], Garg [36], Gheorghiu [37], Ilea [38], Iseki [39], Kasahara [42], A. S. Mureşan [45], [46], V. Mureşan [47]-[50], Nădăban et al. [51], Nagare [52], Namdeo and Gupta [53], Pachpatte [54], Păcurar [55], [56], Păcurar and Rus [57], Pande [58], Pathak and Dubey [59], Petracovici [60], Petruşel and Rus [61], Petruşel et al. [62], Popa [63], Precup [64], Ray [65], Rus [68]-[75], Rzepecki [76]-[78], Sharma [79], Shrivastava and Dubey [80], Shukla and Radenović [81], S. P. Singh [82], S. L. Singh [83], M. R. Singh [84], Trif [85], Turinici [86], [87] etc.

On the other hand, in the recent papers [15]-[20], the authors used the technique of enrichment nonlinear mapings in order to generalize, in the setting of a Banach space, some classes of contractive mappings, amongst which we mention the Banach contractions, for which they introduced and studied the corresponding and larger class of enriched contractions.

Starting from the above facts, the main aim of this paper is to use the approach based on the technique of enrichment of contractive type mappings in order to establish some Maia fixed point theorems for some important classes of enriched contractions in Banach spaces.

\section{MAIA TYPE FIXED POINT THEOREMS FOR ENRICHED CONTRACTIONS}

The concept of enriched contraction has been introduced and studied in [15] as a natural generalization of the classical concept of Banach contraction.

Definition 2.1 (Definition 2.1, [15]). Let $(X,\|\cdot\|)$ be a linear normed space. A mapping $T$ : $X \rightarrow X$ is said to be a $(b, \theta)$-enriched contraction if there exist $b \in[0,+\infty)$ and $\theta \in[0, b+1)$ such that

$$
\|b(x-y)+T x-T y\| \leq \theta\|x-y\|, \forall x, y \in X .
$$

Obviously, any Banach contraction satisfies (2.5) with $b=0$. The next theorem is the main result in [15] and represents an effective generalization of Banach's fixed point theorem in the setting of a Banach space.

Theorem 2.3 ([15]). Let $(X,\|\cdot\|)$ be a Banach space and $T: X \rightarrow X a(b, \theta)$-enriched contraction. Then

(i) Fix $(T)=\{p\}$, for some $p \in X$;

(ii) There exists $\lambda \in(0,1]$ such that the iterative method $\left\{x_{n}\right\}_{n=0}^{\infty}$, given by

$$
x_{n+1}=(1-\lambda) x_{n}+\lambda T x_{n}, n \geq 0,
$$


converges to $p$, for any $x_{0} \in X$;

(iii) The following estimate holds

$$
\left\|x_{n+i-1}-p\right\| \leq \frac{c^{i}}{1-c} \cdot\left\|x_{n}-x_{n-1}\right\|, \quad n=0,1,2, \ldots ; i=1,2, \ldots,
$$

where $c=\frac{\theta}{b+1}$.

We now state a Maia type fixed point theorem for enriched contractions defined on a linear vector space which is endowed with a metric $d$ which is subordinated to a norm $\|\cdot\|$.

Theorem 2.4. Let $X$ be a linear vector space endowed with a metric $d$ and a norm $\|\cdot\|$ satisfying the condition

$$
d(x, y) \leq\|x-y\|, \text { for all } x, y \in X
$$

Suppose

(i) $(X, d)$ is a complete metric space;

(ii) $T: X \rightarrow X$ is continuous with respect to $d$;

(iii) $T$ is an enriched contraction with respect to $\|\cdot\|$, that is, there exist $b \in[0,+\infty)$ and $\theta \in[0, b+1)$ such that

$$
\|b(x-y)+T x-T y\| \leq \theta\|x-y\|, \forall x, y \in X .
$$

Then

(i) Fix $(T)=\{p\}$, for some $p \in X$;

(ii) There exists $\lambda \in(0,1]$ such that the iterative method $\left\{x_{n}\right\}_{n=0}^{\infty}$, given by

$$
x_{n+1}=(1-\lambda) x_{n}+\lambda T x_{n}, n \geq 0,
$$

converges in $(X, d)$ to $p$, for any $x_{0} \in X$;

(iii) The estimate

$$
d\left(x_{n}, p\right) \leq \frac{c^{n}}{1-c} \cdot\left\|x_{1}-x_{0}\right\|, n \geq 1
$$

and

$$
d\left(x_{n}, p\right) \leq \frac{c}{1-c} \cdot\left\|x_{n}-x_{n-1}\right\|, n \geq 1
$$

hold with $c=\frac{\theta}{b+1}$.

Proof. We consider the case $b>0$ (when $b=0$, the proof is immediate). In this case, let us denote $\lambda=\frac{1}{b+1}$. Obviously, $0<\lambda<1$ and the enriched contractive condition (2.8) becomes

$$
\left\|\left(\frac{1}{\lambda}-1\right)(x-y)+T x-T y\right\| \leq \theta\|x-y\|, \forall x, y \in X,
$$

which can be written in an equivalent form as

$$
\left\|T_{\lambda} x-T_{\lambda} y\right\| \leq c \cdot\|x-y\|, \forall x, y \in X,
$$

where we denoted $c=\lambda \theta$, while $T_{\lambda}$ is the averaged mapping defined by

$$
T_{\lambda} x=(1-\lambda) x+\lambda T x, \forall x \in C .
$$

Since $\theta \in(0, b+1)$, it follows that $c \in(0,1)$ and therefore by $(4.44) T_{\lambda}$ is a $c$-contraction. 
In view of (2.13), the Krasnoselskij iterative process $\left\{x_{n}\right\}_{n=0}^{\infty}$ defined by (4.38) is exactly the Picard iteration associated to $T_{\lambda}$, that is,

$$
x_{n+1}=T_{\lambda} x_{n}, n \geq 0 .
$$

Take $x=x_{n}$ and $y=x_{n-1}$ in (4.44) to get

$$
\left\|x_{n+1}-x_{n}\right\| \leq c \cdot\left\|x_{n}-x_{n-1}\right\|, n \geq 1 .
$$

By (4.47) one obtains routinely the following two estimates

$$
\left\|x_{n+m}-x_{n}\right\| \leq c^{n} \cdot \frac{1-c^{m}}{1-c} \cdot\left\|x_{1}-x_{0}\right\|, n \geq 0, m \geq 1 .
$$

and

$$
\left\|x_{n+m}-x_{n}\right\| \leq c \cdot \frac{1-c^{m}}{1-c} \cdot\left\|x_{n}-x_{n-1}\right\|, n \geq 1, m \geq 1
$$

Now, by (4.48) it follows that $\left\{x_{n}\right\}_{n=0}^{\infty}$ is a Cauchy sequence in $(X,\|\cdot\|)$. By the inequality (2.7), we have

$$
d\left(x_{n+m}, x_{n}\right) \leq c^{n} \cdot \frac{1-c^{m}}{1-c} \cdot\left\|x_{1}-x_{0}\right\|, n \geq 0, m \geq 1
$$

which shows that $\left\{x_{n}\right\}_{n=0}^{\infty}$ is a Cauchy sequence in $(X, d)$, too.

Hence $\left\{x_{n}\right\}_{n=0}^{\infty}$ is convergent in $(X,\|\cdot\|)$. Let us denote

$$
p=\lim _{n \rightarrow \infty} x_{n} .
$$

By letting $n \rightarrow \infty$ in (2.14) and, using the continuity of $T_{\lambda}$ with respect to $d$ (which follows by the continuity of $T$ with respect to $d$ ), we immediately obtain

$$
p=T_{\lambda} p \Leftrightarrow p \in \operatorname{Fix}\left(T_{\lambda}\right)
$$

Next, we prove that $p$ is the unique fixed point of $T_{\lambda}$. Assume that $q \neq p$ is another fixed point of $T_{\lambda}$. Then, by (4.44)

$$
0<\|p-q\| \leq c \cdot\|p-q\|<\|p-q\|,
$$

a contradiction. Hence Fix $\left(T_{\lambda}\right)=\{p\}$ and since, by (2.14), Fix $(T)=F i x\left(T_{\lambda}\right)$, claim $(i)$ is proven.

Conclusion (ii) follows by (4.50).

To prove ( $i i i)$, we first observe that by combining (4.48) and (4.49) and (2.7), one obtains

$$
d\left(x_{n+m}, x_{n}\right) \leq c^{n} \cdot \frac{1-c^{m}}{1-c} \cdot\left\|x_{1}-x_{0}\right\|, n \geq 0, m \geq 1
$$

and

$$
d\left(x_{n+m}, x_{n}\right) \leq c \cdot \frac{1-c^{m}}{1-c} \cdot\left\|x_{n}-x_{n-1}\right\|, n \geq 1, m \geq 1 .
$$

Now, we let $m \rightarrow \infty$ in (3.34) and (3.35) to get the desired estimate (2.10):

$$
d\left(x_{n}, p\right) \leq \frac{c^{n}}{1-c} \cdot\left\|x_{1}-x_{0}\right\|, n \geq 1
$$

and (2.11):

$$
d\left(x_{n}, p\right) \leq \frac{c}{1-c} \cdot\left\|x_{n}-x_{n-1}\right\|, n \geq 1
$$

respectively, where $c=\frac{\theta}{b+1}$. 
Remark 2.3. If $d(x, y)=\|x-y\|$, for all $x, y \in X$, then by Theorem 2.4 we obtain Theorem 2.3.

In this case, the two estimates (2.10) and (2.11) in Theorem 2.4 can be merged to yield the unified estimate (2.6) in Theorem 2.3.

\section{MAIA TYPE FIXED POINT THEOREMS FOR ENRICHED KANNAN CONTRACTIONS}

The concept of enriched Kannan contraction has been introduced and studied in [16] as a natural generalization of that of Kannan mappings [40], [41], which are self mapings $T: X \rightarrow X$ satisfying the Kannan's contraction condition

$$
d(T x, T y) \leq b(d(x, T x)+d(y, T y)), \text { for all } x, y \in X,
$$

where $b \in[0,1 / 2)$ is a constant.

Definition 3.2 ([16], Definition 2.1). Let $(X,\|\cdot\|)$ be a normed linear space. A mapping $T: X \rightarrow X$ is said to be a $(k, a)$-enriched Kannan mapping if there exist $a \in[0,1 / 2)$ and $k \in[0, \infty)$ such that

$$
\|k(x-y)+T x-T y\| \leq a(\|x-T x\|+\|y-T y\|), \text { for all } x, y \in X .
$$

Obviously, any Kannan mapping satisfies (3.22) with $k=0$.

The next theorem, the main result in [16], is a genuine generalization of the Kannan fixed point theorem in the setting of Banach spaces, see Example 2.1 in [16].

Theorem $3.5([16])$. Let $(X,\|\cdot\|)$ be a Banach space and $T: X \rightarrow X a(k, a)$-enriched Kannan mapping. Then

(i) Fix $(T)=\{p\}$, for some $p \in X$;

(ii) There exists $\lambda \in(0,1]$ such that the iterative method $\left\{x_{n}\right\}_{n=0}^{\infty}$, given by

$$
x_{n+1}=(1-\lambda) x_{n}+\lambda T x_{n}, n \geq 0,
$$

converges to $p$, for any $x_{0} \in X$;

(iii) The following estimate holds

$$
\left\|x_{n+i-1}-p\right\| \leq \frac{\delta^{i}}{1-\delta} \cdot\left\|x_{n}-x_{n-1}\right\|, \quad n=0,1,2, \ldots ; i=1,2, \ldots
$$

where $\delta=\frac{a}{1-a}$.

Our aim in this section is to extend 3.5 and thus obtain a Maia type fixed point theorem for enriched Kannan contractions in Banach spaces.

Theorem 3.6. Let $X$ be a linear vector space endowed with a metric d and a norm $\|\cdot\|$ satisfying the condition

$$
d(x, y) \leq\|x-y\|, \text { for all } x, y \in X .
$$

Suppose

(i) $(X, d)$ is a complete metric space; (ii) $T: X \rightarrow X$ is continuous with respect to $d$;

(iii) $T$ is an enriched Kannan contraction with respect to $\|\cdot\|$, that is, there exist $a \in[0,1 / 2)$ and $k \in[0, \infty)$ such that (3.22) holds.

Then

(i) Fix $(T)=\{p\}$, for some $p \in X$;

(ii) There exists $\lambda \in(0,1]$ such that the iterative method $\left\{x_{n}\right\}_{n=0}^{\infty}$, given by

$$
x_{n+1}=(1-\lambda) x_{n}+\lambda T x_{n}, n \geq 0,
$$

converges in $(X, d)$ to $p$, for any $x_{0} \in X$; 
(iii) The following estimates hold

$$
d\left(x_{n}, p\right) \leq \frac{\delta^{n}}{1-\delta} \cdot\left\|x_{1}-x_{0}\right\|, n \geq 1
$$

and

$$
d\left(x_{n}, p\right) \leq \frac{\delta}{1-\delta} \cdot\left\|x_{n}-x_{n-1}\right\|, n \geq 1
$$

where $\delta=\frac{a}{1-a}$.

Proof. We analyze the case when $k>0$ (the case $k=0$ is immediate). Consider the averaged mapping $T_{\lambda}$ for $\lambda=\frac{1}{k+1}$, as $0<\lambda<1$. In this case we have that $k=1 / \lambda-1$ and thus the contractive condition (3.22) becomes

$$
\left\|\left(\frac{1}{\lambda}-1\right)(x-y)+T x-T y\right\| \leq a(\|x-T x\|+\|y-T y\|), \text { for all } x, y \in X,
$$

which can be written in an equivalent form as

$$
\left\|T_{\lambda} x-T_{\lambda} y\right\| \leq a\left(\left\|x-T_{\lambda} x\right\|+\left\|y-T_{\lambda} y\right\|\right), \text { for all } x, y \in X .
$$

The above inequality shows that $T_{\lambda}$ is a Kannan mapping.

According to (2.13), the iterative process $\left\{x_{n}\right\}_{n=0}^{\infty}$ defined by (3.25) is the Picard iteration associated to $T_{\lambda}$, that is,

$$
x_{n+1}=T_{\lambda} x_{n}, n \geq 0 .
$$

Take $x=x_{n}$ and $y=x_{n-1}$ in (4.44) to get

$$
\left\|x_{n+1}-x_{n}\right\| \leq a\left(\left\|x_{n}-x_{n+1}\right\|+\left\|x_{n}-x_{n-1}\right\|\right),
$$

which yields

$$
\left\|x_{n+1}-x_{n}\right\| \leq \frac{a}{1-a}\left\|x_{n}-x_{n-1}\right\|, n \geq 1 .
$$

Since $0<a<\frac{1}{2}$, by denoting $\delta=\frac{a}{1-a}$, we have $0<\delta<1$ and therefore the sequence $\left\{x_{n}\right\}_{n=0}^{\infty}$ satisfies

$$
\left\|x_{n+1}-x_{n}\right\| \leq \delta\left\|x_{n}-x_{n-1}\right\|, n \geq 1 .
$$

By (4.47) one obtains routinely the following two estimates

$$
\left\|x_{n+m}-x_{n}\right\| \leq \delta^{n} \cdot \frac{1-\delta^{m}}{1-\delta} \cdot\left\|x_{1}-x_{0}\right\|, n \geq 0, m \geq 1
$$

and

$$
\left\|x_{n+m}-x_{n}\right\| \leq \delta \cdot \frac{1-\delta^{m}}{1-\delta} \cdot\left\|x_{n}-x_{n-1}\right\|, n \geq 1, m \geq 1 .
$$

Now, by (4.48) and the inequality (3.24), we have

$$
d\left(x_{n+m}, x_{n}\right) \leq \delta^{n} \cdot \frac{1-\delta^{m}}{1-\delta} \cdot\left\|x_{1}-x_{0}\right\|, n \geq 0, m \geq 1
$$

which shows that $\left\{x_{n}\right\}_{n=0}^{\infty}$ is a Cauchy sequence in the complete metric space $(X, d)$, hence it is convergent.

Let us denote

$$
p=\lim _{n \rightarrow \infty} x_{n}
$$

By the continuity of $T$ with respect to $d$ it follows that $T_{\lambda}$ is also continuous with respect to $d$ and therefore by passing to the limit in (3.29) we obtain $p \in F i x\left(T_{\lambda}\right)$. 
To prove that $p$ is the unique fixed point of $T_{\lambda}$, assume that $q \neq p$ is another fixed point of $T_{\lambda}$. Then, by (4.44) we get

$$
0<\|p-q\| \leq a \cdot 0,
$$

a contradiction. Hence Fix $\left(T_{\lambda}\right)=\{p\}$ and since Fix $(T)=F i x\left(T_{\lambda}\right),(i)$ is proven.

Conclusion $(i i)$ now follows by (4.50).

To prove ( $i i i)$, we first observe that by combining (4.48) and (4.49) with (2.7), one obtains

$$
d\left(x_{n+m}, x_{n}\right) \leq \delta^{n} \cdot \frac{1-\delta^{m}}{1-\delta} \cdot\left\|x_{1}-x_{0}\right\|, n \geq 0, m \geq 1
$$

and

$$
d\left(x_{n+m}, x_{n}\right) \leq \delta \cdot \frac{1-\delta^{m}}{1-\delta} \cdot\left\|x_{n}-x_{n-1}\right\|, n \geq 1, m \geq 1,
$$

respectively. Now, we let $m \rightarrow \infty$ in (3.34) and (3.35) to get the desired estimates (3.26) and (3.27).

Remark 3.4. If $d(x, y)=\|x-y\|$, for all $x, y \in X$, then by Theorem 3.6 we obtain Theorem 3.5 .

In this case, the two estimates (3.26) and (3.27) in Theorem 3.6 can be merged to yield the unified estimate in Theorem 3.5.

\section{MAIA FIXED POINT THEOREM FOR ENRICHED ĆIRIĆ-REICH-RUS CONTRACTIONS}

Let $(X, d)$ be a metric space. In 1971, Ćirić [29], Reich [66] and Rus [67] have established independently a very nice fixed point theorem for mappings $T: X \rightarrow X$ satisfying the following condition:

$$
d(T x, T y) \leq a d(x, y)+b(d(x, T x)+d(y, T y)), \text { for all } x, y \in X,
$$

where $a, b \geq 0$ and $a+2 b<1$.

We remark that if $b=0$, condition (4.36) reduces to Banach's contraction condition (1.1) while, for $a=0$ condition (4.36) reduces to Kannan's contraction condition (3.21).

Therefore, the fixed point results established in [29], [66] and [67], under slightly different forms, are genuine generalizations of the Banach's contraction principle [8], [26] and of Kannan's fixed point theorem [40], see also [41], as shown by examples in [21].

Our aim in this section is to unify and extend Theorems 2.4 and 3.6 and thus obtain a Maia type fixed point theorem for enriched Ćirić-Reich-Rus contractions in Banach spaces.

To this end we need the following concept introduced in [21].

Definition 4.3 ([21], Definition 2.3). Let $(X,\|\cdot\|)$ be a linear normed space. A mapping $T: X \rightarrow X$ is said to be a $(k, a, b)$-enriched Ćirić-Reich-Rus contraction if there exist $a, b \geq 0$ satisfying $a+2 b<1$ and $k \in[0, \infty)$ such that

$$
\|k(x-y)+T x-T y\| \leq a\|x-y\|+b(\|x-T x\|+\|y-T y\|) \text {, for all } x, y \in X .
$$

Obviously, any Ćirić-Reich-Rus contraction satisfies (4.37) with $k=0$.

Also, if $b=0$, then from (4.37) we obtain the contraction condition (2.5) satisfied by an enriched contraction, while, if $a=0$, from (4.37) we obtain the enriched Kannan contraction condition (3.22). Amongst the main results in [21] we recall the next theorem.

Theorem 4.7 ([21], Theorem 2.3). Let $(X,\|\cdot\|)$ be a Banach space and $T: X \rightarrow X a(k, a, b)$ enriched Ćirić-Reich-Rus contraction. Then

(i) Fix $(T)=\{p\}$, for some $p \in X$; 
(ii) There exists $\lambda \in(0,1]$ such that the iterative method $\left\{x_{n}\right\}_{n=0}^{\infty}$, given by

$$
x_{n+1}=(1-\lambda) x_{n}+\lambda T x_{n}, n \geq 0,
$$

converges to $p$, for any $x_{0} \in X$;

(iii) The following estimate holds

$$
\left\|x_{n+i-1}-p\right\| \leq \frac{\delta^{i}}{1-\delta} \cdot\left\|x_{n}-x_{n-1}\right\|, \quad n=0,1,2, \ldots ; i=1,2, \ldots
$$

where $\delta=\frac{a+b}{1-b}$.

The aim of this section is to extend Theorem 4.7 and thus obtain a Maia type fixed point theorem for enriched Ćirić-Reich-Rus contractions in Banach spaces..

Theorem 4.8. Let $X$ be a linear vector space endowed with a metric $d$ and a norm $\|\cdot\|$ satisfying the condition

$$
d(x, y) \leq\|x-y\|, \text { for all } x, y \in X .
$$

Suppose

(i) $(X, d)$ is a complete metric space; (ii) $T: X \rightarrow X$ is continuous with respect to $d$;

(iii) $T$ is an enriched Ćirić-Reich-Rus contraction with respect to $\|\cdot\|$, that is, there exist $a, b \geq 0$ satisfying $a+2 b<1$ and $k \in[0, \infty)$ such that (4.37) holds.

Then

(i) Fix $(T)=\{p\}$, for some $p \in X$;

(ii) There exists $\lambda \in(0,1]$ such that the iterative method $\left\{x_{n}\right\}_{n=0}^{\infty}$, given by

$$
x_{n+1}=(1-\lambda) x_{n}+\lambda T x_{n}, n \geq 0,
$$

converges in $(X, d)$ to $p$, for any $x_{0} \in X$;

(iii) The following estimates hold

$$
d\left(x_{n}, p\right) \leq \frac{\delta^{n}}{1-\delta} \cdot\left\|x_{1}-x_{0}\right\|, n \geq 1
$$

and

$$
d\left(x_{n}, p\right) \leq \frac{\delta}{1-\delta} \cdot\left\|x_{n}-x_{n-1}\right\|, n \geq 1
$$

where $\delta=\frac{a+b}{1-a}$.

Proof. First we work in the case when $k>0$ (the case $k=0$ is similar) and consider the averaged mapping $T_{\lambda}$ defined by (2.13) for $\lambda=\frac{1}{k+1}<1$.

In this case we have that $k=1 / \lambda-1$ and thus the contractive condition (4.37) becomes

$$
\left\|\left(\frac{1}{\lambda}-1\right)(x-y)+T x-T y\right\| \leq a\|x-y\|+b(\|x-T x\|+\|y-T y\|) \text {, for all } x, y \in X,
$$

which can be written equivalently as

$$
\left\|T_{\lambda} x-T_{\lambda} y\right\| \leq a \lambda\|x-y\|+b\left(\left\|x-T_{\lambda} x\right\|+\left\|y-T_{\lambda} y\right\|\right), \text { for all } x, y \in X,
$$

and, because $a \lambda \leq a$, this implies that

$$
\left\|T_{\lambda} x-T_{\lambda} y\right\| \leq a\|x-y\|+b\left(\left\|x-T_{\lambda} x\right\|+\left\|y-T_{\lambda} y\right\|\right) \text {, for all } x, y \in X,
$$

which means that $T_{\lambda}$ is a Ćirić-Reich-Rus contraction mapping.

By using triangle inequality in (4.44), we obtain that $T_{\lambda}$ satisfies

$$
\left\|T_{\lambda} x-T_{\lambda} y\right\| \leq \delta \cdot\|x-y\|+2 \delta \cdot\left\|y-T_{\lambda} x\right\| \text {, for all } x, y \in X,
$$


where $\delta=\frac{a+b}{1-b}<1$.

Consider the iterative process $\left\{x_{n}\right\}_{n=0}^{\infty}$ defined by (4.38), which is in fact the Picard iteration associated to $T_{\lambda}$, that is,

$$
x_{n+1}=T_{\lambda} x_{n}, n \geq 0 .
$$

and take $x=x_{n}$ and $y=x_{n-1}$ in (4.45) to get

$$
\left\|x_{n+1}-x_{n}\right\| \leq \delta\left\|x_{n}-x_{n-1}\right\|, n \geq 1 .
$$

By (4.47) one obtains routinely the following two estimates

$$
\left\|x_{n+m}-x_{n}\right\| \leq \delta^{n} \cdot \frac{1-\delta^{m}}{1-\delta} \cdot\left\|x_{1}-x_{0}\right\|, n \geq 0, m \geq 1
$$

and

$$
\left\|x_{n+m}-x_{n}\right\| \leq \delta \cdot \frac{1-\delta^{m}}{1-\delta} \cdot\left\|x_{n}-x_{n-1}\right\|, n \geq 1, m \geq 1 .
$$

Now, by (4.48) and the subordination inequality (4.40), we have

$$
d\left(x_{n+m}, x_{n}\right) \leq \delta^{n} \cdot \frac{1-\delta^{m}}{1-\delta} \cdot\left\|x_{1}-x_{0}\right\|, n \geq 0, m \geq 1
$$

which shows that $\left\{x_{n}\right\}_{n=0}^{\infty}$ is a Cauchy sequence in the complete metric space $(X, d)$, hence it is convergent. Let us denote

$$
p=\lim _{n \rightarrow \infty} x_{n} .
$$

To prove that $p$ is a fixed point of $T_{\lambda}$, observe that by the continuity of $T$ with respect to $d$ it follows that $T_{\lambda}$ is continuous with respect to $d$, too and therefore by passing to the limit in (4.46) we obtain $p \in F i x\left(T_{\lambda}\right)$.

Assume, that $q \neq p$ is another fixed point of $T_{\lambda}$. Then, by (4.44) with $x=p$ and $y=q$ it follows

$$
0<\|p-q\| \leq a\|p-q\|<\|p-q\|,
$$

a contradiction. Hence Fix $\left(T_{\lambda}\right)=\{p\}$ and since Fix $(T)=F i x\left(T_{\lambda}\right),(i)$ is proven.

Conclusion $(i i)$ follows by (4.50).

The rest of the proof is similar to that of Theorem 3.6.

Remark 4.5. In the particular case $a=0$, by Theorem 4.8 we obtain Theorem 3.6, while, for $b=0$, by Theorem 4.8 we obtain Theorem 2.4 .

If $d(x, y)=\|x-y\|$, for all $x, y \in X$ and $a=0$, then by Theorem 4.8 we get Theorem 3.5, while, for $a=0$, we get Theorem 2.3.

In both these cases, the two estimates (4.42) and (4.43) in Theorem 4.8 can be merged to yield the unified estimate in Theorems 3.5 and 2.3.

\section{CONCLUSIONS}

1. Using the technique of enriching contractive type mappings $T$ by means of the averaged operator $T_{\lambda}$, we established some Maia fixed point theorems for three important classes of enriched contractive mappings in Banach spaces.

2. The obtained fixed point theorems are important generalizations of the corresponding results for enriched contractions, enriched Kannan mappings and Ćirić-Reich-Rus contractions in Banach spaces, respectively.

3. Similar Maia fixed point theorems could be obtained by applying the technique of enriching nonlinear operators for the classes of contractive mappings studied in [1], [4], [5]-[7], [9], [10], [22], [23], [25], [30]-[39], [42], [45]-[87] etc. 
Acknowledgments. I am expressing in this way my gratitude to have had the unique chance to join, on 1st October 1990, as a debutant Assistant Professor, the University of Baia Mare (renamed North University of Baia Mare in 1996 and, since 2012, North University Centre at Baia Mare, as part of the Technical University of Cluj-Napoca), where I continued to work for more than 30 years.

Looking back, I am forever thankful I chose to continue working in a small community despite more prestigious academic temptations. My small university was the ideal place and the most significant stepping stone to starting my academic career, being close to my birthplace and my family - a fact that ensured me a very productive mental and social comfort.

Not only has it opened to me a large avenue to develop myself academically, but also offered me the opportunity to grow both as a researcher and a university administrator. Although I was coming from the software industry, where I spent eleven years as a computer programmer, at University of Baia Mare I was able to smoothly develop the specific skills necessary to reach all my academic achievements.

\section{REFERENCES}

[1] Albu, M. A fixed point theorem of Maia-Perov type. Studia Univ. Babeş-Bolyai Math. 23 (1978), no. 1, 76-79.

[2] Agarwal, R. P.; O'Regan, D.; Sahu, D. R. Fixed point theory for Lipschitzian-type mappings with applications. in Topological Fixed Point Theory and Its Applications, 6. Springer, New York, 2009.

[3] Alghamdi, Maryam A.; Berinde, V.; Shahzad, N. Fixed points of multivalued nonself almost contractions. J. Appl. Math. 2013, Art. ID 621614, 6 pp.

[4] Ansari, A. H.; Khan, M. S.; Rakočević, V. Maia type fixed point results via $C$-class function. Acta Univ. Sapientiae Math. 12 (2020), no. 2, 227-244.

[5] Balazs, M.-E. A Maia type fixed point theorem for Prešić-Kannan operators. Miskolc Math. Notes 18 (2017), no. 1,71-81.

[6] Balazs, M.-E. Maia type fixed point theorems for Ćirić-Prešić operators. Acta Univ. Sapientiae Math. 10 (2018), no. 1, 18-31.

[7] Balazs, M.-E. Maia type fixed point theorems for Prešić type operators. Fixed Point Theory 20 (2019), no. 1, 59-70.

[8] Banach, S. Sur les opérations dans les ensembles abstraits et leurs applications aux équations intégrales. Fundam. Math.3 (1922), 133-181.

[9] Bayen, D. K. Some remarks on fixed point theorems. Mathematica (Cluj) 29(52) (1987), no. 1, 1-5.

[10] Berinde, V. A fixed point theorem of Maia type in K-metric spaces. Seminar on Fixed Point Theory. "BabeşBolyai" Univ. Cluj-Napoca, 91-3 (1992), 7-14.

[11] Berinde, V. Iterative Approximation of Fixed Points, Springer, 2007.

[12] Berinde, V. Approximating fixed points of implicit almost contractions. Hacettepe J. Math. Stat. 41 (2012), no. $1,93-102$.

[13] Berinde, V.; Păcurar, M. Coupled fixed point theorems for generalized symmetric Meir-Keeler contractions in ordered metric spaces. Fixed Point Theory Appl. 2012, 2012:115, 11 pp.

[14] Berinde, V.; Păcurar, M. Fixed point theorems for nonself single-valued almost contractions. Fixed Point Theory 14 (2013), no. 2, 301-311.

[15] Berinde, V.; Păcurar, M. Approximating fixed points of enriched contractions in Banach spaces. J. Fixed Point Theory Appl. 22 (2020), no. 2, Paper 38, 10 pp.

[16] Berinde, V.; Păcurar, M., Kannan's fixed point approximation for solving split feasibility and variational inequality problems. J. Comput. Appl. Math. 386 (2021), 113217, 9 pp.

[17] Berinde, V.; Păcurar, M., Fixed point theorems for Chatterjea type mappings in Banach spaces. J. Fixed Point Theory Appl. (submitted)

[18] Berinde, V.; Păcurar, M. Iterative approximation of fixed points of single-valued almost contractions, in Fixed Point Theory and Graph Theory, 29-97, Elsevier/Academic Press, Amsterdam, 2016.

[19] Berinde, V.; Păcurar, M. Existence and Approximation of Fixed Points of Enriched Contractions and Enriched $\varphi$-Contractions. Symmetry 13 (2021), no. 3, Article no.: 498. https:/ / doi.org/10.3390/sym13030498.

[20] Berinde, V.; Păcurar, M. Krasnoselskij-type algorithms for variational inequality problems and fixed point problems in Banach spaces. arXiv:2103.10289

[21] Berinde, V.; Păcurar, M. Fixed point theorems for enriched Ćirić-Reich-Rus contractions in Banach spaces and convex metric spaces. Carpathian J. Math. 37 (2021), no. 2 (in press). 
[22] Berinde, V.; Vetro, F. Fixed point for cyclic weak $(\Psi, C)$-contractions in 0-complete partial metric spaces. Filomat 27 (2013), no. 8, 1405-1413.

[23] Bhola, P. K.; Sharma, P. L. A common fixed point theorem for multivalued mapping in complete metric space. Math. Educ. 26 (1992), No. 3, 172-173.

[24] Browder, F. E. and Petryshyn, W. V., Construction of fixed points of nonlinear mappings in Hilbert space, J. Math. Anal. Appl. 20 (1967), 197-228.

[25] Bylka, C.; Rzepecki, B. Results on fixed points. Demonstratio Math. 17 (1984), no. 1, 97-106.

[26] Caccioppoli, R. Un teorema generale sull'esistenza di elementi uniti in una transformazione funzionale. Rend. Accad. Lincei. 11 (1930), 794-799.

[27] Chatterjea, S.K. Fixed-point theorems. C. R. Acad. Bulgare Sci. 25 (1972), 727-730.

[28] Choban, M.M. About convex structures on metric spaces. Carpathian J. Math. 37 (2021) (in press).

[29] Ćirić, L. B. Generalized contractions and fixed-point theorems. Publ. Inst. Math. (Beograd) (N.S.) 12(26) (1971), 19-26.

[30] Dhage, B. C. On extension of a fixed point theorem of Maia. Pure Appl. Math. Sci. 24 (1986), no. 1-2, 65-69.

[31] Dhage, B. C. On unified generalisation of fixed point theorems of Banach and Maia. Math. Ed. (Siwan) 21 (1987), no. 3, 79-83.

[32] Dhage, B. C.; Dhobale, V. V. On generalization of Maia's fixed point theorem. J. Indian Acad. Math. 8 (1986), no. $1,25-30$.

[33] Dhage, B. C. On Kannan type maps in D-metric spaces. J. Nat. Phys. Sci. 11 (1997), 21-38.

[34] Filip, A.-D. Perov's fixed point theorem for multivalued mappings in generalized Kasahara spaces. Stud. Univ. Babeş-Bolyai Math. 56 (2011), no. 3, 19-28.

[35] Filip, A.-D. Fixed point theorems for multivalued contractions in Kasahara spaces. Carpathian J. Math. 31 (2015), no. 2, 189-196.

[36] Garg, R. On a fixed point theorem in a metric space with two metrics. Math. Educ. 31 (1997), No. 3, 134-137.

[37] Gheorghiu, N. Fixed point theorems in uniform spaces. An. Ştiinţ. Univ. "Al. I. Cuza" Iaşi Secţ. I a Mat. (N.S.) 28 (1982), no. 1, 17-18.

[38] Ilea, V. A.; Şerban, M.-A. An existence result of the solution for mixed type functional differential equations with parameter. Nonlinear Anal. Forum 12 (2007), no. 1, 59-65.

[39] Iséki, K. Common fixed points of mappings. Tamkang J. Math. 6 (1975), no. 2, 157-159.

[40] Kannan, R., Some results on fixed points. Bull. Calcutta Math. Soc. 60 (1968), 71-76.

[41] Kannan, R., Some results on fixed points. II. Am. Math. Monthly, 76 (1969), 405-408.

[42] Kasahara, S. On some generalizations of the Banach contraction theorem. Publ. Res. Inst. Math. Sci. 12 (1976/77), no. 2, 427-437.

[43] Khan, S.H.; Abbas, M. Common fixed point results with applications in convex metric spaces. J. Concr. Appl. Math. 10 (2012), 65-76.

[44] Maia, M. G. Un'osservazione sulle contrazioni metriche. (Italian) Rend. Sem. Mat. Univ. Padova 40 (1968), $139-143$.

[45] Mureşan, A. S. Some fixed point theorems of Maia type. Seminar on Fixed Point Theory. Univ. "Babeş-Bolyai" Cluj-Napoca, 88-3 (1988), 35-42.

[46] Mureşan, A. S. From Maia fixed point theorem to the fixed point theory in a set with two metrics. Carpathian J. Math. 23 (2007), no. 1-2, 133-140.

[47] Mureşan, V. Basic problem for Maia-Perov's fixed point theorem. Seminar on Fixed Point Theory. Univ. "BabeşBolyai" Cluj-Napoca. 88-3 (1988), 43-48.

[48] Mureşan, V. Basic problem for Maia-Perov's fixed point theorem. Seminar on Fixed Point Theory. Univ. "BabeşBolyai" Cluj-Napoca. 88-3 (1988), 43-48.

[49] Mureşan, V. Existence, uniqueness and data dependence for the solution to a boundary value problem with deviating argument. P.U.M.A., Pure Math. Appl. 11 (2000), No. 2, 341-349.

[50] Mureşan, V. Functional-integral equations. Editura Mediamira, Cluj-Napoca, 2003.

[51] Nădăban, S.; Bînzar, T.; Pater, F. Some fixed point theorems for $\varphi$-contractive mappings in fuzzy normed linear spaces. J. Nonlinear Sci. Appl. 10 (2017), no. 11, 5668-5676.

[52] Nagare, I. L.; Dhage, B. C. On sequences of contraction mappings in a metric space. Pure Appl. Math. Sci. 29 (1989), no. 1-2, 95-97.

[53] Namdeo, R. K.; Gupta, D. Some fixed point theorems in bimetric space. Acta Cienc. Indica, Math. 19 (1993), No. 4, 201-203.

[54] Pachpatte, B. G. On a family of contractive maps. Bul. Ştiinţ. Tehn. Inst. Politehn. "Traian Vuia" Timişoara Ser. Mat. Fiz. 26(40) (1981), no. 2, 53-60.

[55] Păcurar, M. Iterative methods for fixed point approximation, Editura Risoprint, Cluj-Napoca, 2009.

[56] Păcurar, M. Fixed point theory for cyclic Berinde operators. Fixed Point Theory 12 (2011), No. 2, 419-428. 
[57] Păcurar, M.; Rus, I. A. Fixed point theory for cyclic $\phi$-contractions. Nonlinear Anal. 72 (2010), no. 3-4, 1181-1187.

[58] Pande, R. K. On fixed point theorem in a space with two metrics. Math. Ed. (Siwan) 23 (1989), no. 2 , 65-67.

[59] Pathak, H. K.; Dubey, R. P. Comment on the fixed point theorem of Maia. Math. Ed. (Siwan) bf 25 (1991), no. 3, 175-178.

[60] Petracovici, B. Nonlinear two-point boundary value problems. Seminar on Differential Equations. Univ. "Babeş-Bolyai" Cluj-Napoca. 89-3 (1989), 1-12.

[61] Petruşel, A.; Rus, I. A. Fixed point theory for multivalued operators on a set with two metrics. Fixed Point Theory 8 (2007), no. 1, 97-104.

[62] Petruşel, A.; Rus, I. A.; Şerban, M. A. Fixed points for operators on generalized metric spaces. Cubo 10 (2008), no. 4, 45-66.

[63] Popa, V. Some theorems on common fixed points. J. Maulana Azad College Tech. 20 (1987), 101-106.

[64] Precup, R. A fixed point theorem of Maia type in syntopogenous spaces. Seminar on Fixed Point Theory. Univ. "Babeş-Bolyai" Cluj-Napoca, 88-3 (1988), 49-70.

[65] Ray, B. On a fixed point theorem in a space with two metrics. Math. Education 9 (1975), no. 3, A57-A58.

[66] Reich, S., Some remarks concerning contraction mappings. Canad. Math. Bull. 14 (1971), 121-124.

[67] Rus, I.A., Some fixed point theorems in metric spaces. Rend. Istit. Mat. Univ. Trieste 3 (1971), 169-172 (1972).

[68] Rus, I. A. On a fixed point theorem of Maia. Studia Univ. Babeş-Bolyai Math. 22 (1977), 40-42.

[69] Rus, I. A. Basic problem for Maia's theorem. Seminar on Fixed Point Theory. Univ. "Babeş-Bolyai" Cluj-Napoca, 81-3 (1981), 112-115.

[70] Rus, I. A. Generalized Contractions and Applications, Cluj Univ. Press, Cluj-Napoca, 2001.

[71] Rus, I. A. Picard operators and applications, Sci. Math. Jpn., 58 (2003), no. 1, 191-219.

[72] Rus, I. A. Heuristic introduction to weakly Picard operator theory, Creat. Math. Inform., 23 (2014), no. 2, $243-252$.

[73] Rus, I. A.; Petruşel A.; Petruşel, G., Fixed Point Theory, Cluj University Press, Cluj-Napoca, 2008.

[74] Rus, I. A. Iterates of increasing linear operators, via Maia's fixed point theorem. Stud. Univ. Babeş-Bolyai Math. 60 (2015), no. 1, 91-98.

[75] Rus, I. A. Data dependence of the fixed points in a set with two metrics. Fixed Point Theory 8 (2007), no. 1, 115-123.

[76] Rzepecki, B. A note on fixed point theorem of Maia. Studia Univ. Babeş-Bolyai Math. 25 (1980), no. 2, 65-71.

[77] Rzepecki, B. On fixed point theorems of Maia type. Publ. Inst. Math. (Beograd) (N.S.) 28 (42) (1980), $179-186$.

[78] Rzepecki, B. Remarks on the Banach fixed point principle and its applications. Rev. Roumaine Math. Pures Appl. 27 (1982), no. 1, 81-93.

[79] Sharma, R. S. Fixed point theorem in bi-metric space. Acta Cienc. Indica, Math. 17, No. 2, 347-350 (1991)

[80] Shrivastava, K. C.; Dubey, P. K. Some results in bimetric space. Acta Cienc. Indica, Math. 18 (1992), No. 1, 95-98.

[81] Shukla, S.; Radenović, S. Prešić-Maia type theorems in ordered metric spaces. Gulf J. Math. 2 (2014), No. 2, 73-82.

[82] Singh, S. P. On fixed point theorems. Seminar in Analysis, 1974, pp. 1-37. Matscience, No. 5, Inst. Math. Sci., Madras, 1976.

[83] Singh, K. L. A note on common fixed points. Bull. Math. Soc. Sci. Math. R. S. Roumanie (N.S.) 22(70) (1978), no. 1, 95-98.

[84] Singh, M. R. Results on continuous mappings and fixed points in a 2-metric space using two metrics. J. Indian Acad. Math. 11 (1989), no. 1, 39-44.

[85] Trif, D. The Maia type fixed point theorem in the alternative method. Seminar on Fixed Point Theory. Univ. "Babeş-Bolyai" Cluj-Napoca 88-3 (1988), 29-34.

[86] Turinici, M. Ran-Reurings fixed point results in ordered metric spaces. Libertas Math. 31 (2011), 49-55.

[87] Turinici, M. Contraction maps in ordered metrical structures. in Pardalos, Panos M. (ed.) et al., Mathematics without boundaries. Surveys in interdisciplinary research. Springer, New York, 2014, 533-575.

\author{
Department of MATHEMAtics And COMPUter SCIENCE \\ TECHNICAL UNIVERSITY OF CLUJ-NAPOCA \\ North University Centre at Baia Mare \\ VictORIEI 76, RO-430122 BAIA MARE, ROMANIA \\ Email address: vasile.berinde@mi.utcluj.ro
}

ACADEMY OF ROMANIAN SCIENTISTS

Email address: vasile.berinde@gmail.com 